\title{
Cluster headache and its cousins: A family of pain management problems
}

John Edmeads MD

\section{J Edmeads.}

Cluster headache and its cousins: A family of pain management problems.

Pain Res Manage 2000;5(1):58-63.

Cluster headache causes great misery because of the severity, frequency and repetitiveness of its attacks, and the fear (justified in a few sufferers) that the attacks will respond to nothing and will never cease. For most people with cluster headaches there is effective treatment, both for the acute attacks (subcutaneous sumatriptan, injected dihydroergotamine and oxygen inhalation) and for prophylaxis (verapamil, valproate, ergotamine, methysergide, lithium carbonate and corticosteroids). For the $10 \%$ of suffers who respond to no medications, or have to discontinue them because of serious adverse effects, surgical ablation of the trigeminal root or nervus intermedius is a last resort that helps only some.

Correct diagnosis is an essential prelude to an appropriate treatment. Serious disease such as carotid dissection, and aneurysm may occasionally mimic cluster headache, but seldom perfectly enough to confuse a careful clinician. In terms of sorting out the diagnosis, the recently recognized relatives of cluster headache chronic and episodic paroxysmal hemicrania, and short-lasting unilateral neuralgiform headache with conjunctival injection and tearing syndrome - are more problematic. These are important to recognize because they do not respond to 'cluster treatment', but the paroxysmal hemicranias respond to indomethacin, whereas the cluster headache does not. A more distant family member, hemicrania continua, is usually, but not always, responsive to indomethacin and sometimes bears a passing resemblance to cluster headache. An unrelated entity, hypnic headache, has confused a few clinicians who did not bear in mind that a detailed history is the key to headache diagnosis.

Key Words: Chronic paroxysmal hemicrania; Cluster headache; Hemicrania continua; Hypnic headache; SUNCT syndrome

\section{La céphalée vasculaire de Horton et ses proches parents : une famille difficile à traite}

RÉSUMÉ: La céphalée vasculaire de Horton rend très pénible la vie de ceux et celles qui en sont victimes à cause de la gravité, de la fréquence et du caractère répétitif de ses accès, et des craintes (parfois justifiées) que rien ne saura la soulager et qu'elle ne prendra jamais fin. Pourtant, il existe, dans la plupart des cas, un traitement efficace, tant pour les accès (sumatriptan sous-cutané, dihydroergotamine en injection, inhalation d'oxygène) que pour leur prévention (vérapamil, valproate, ergotamine, méthysergide, carbonate de lithium, corticostéroïdes). Dans les $10 \%$ de cas où les médicaments s'avèrent inefficaces ou entraînent des effets indésirables graves, l'ablation de la racine du voir page suivante 
trijumeau ou du nerf intermédiaire de Wrisberg s'avère le traitement de dernier recours, mais il ne soulage que quelques patients seulement. Un élément essentiel au traitement est la pose du bon diagnostic. Des maladies graves comme les dissections et les anévrismes de la carotide peuvent parfois simuler la céphalée vasculaire de Horton et, en de rares occasions, même tromper le clinicien averti. Pour ce qui est des proches parents de la céphalée vasculaire de Horton, reconnus depuis peu, l'hémicrânie paroxystique chronique et épisodique et les céphalées unilatérales brèves, qui ressemblent à des névralgies et qui sont accompagnées d'injections conjonctivales et de larmoiement, le diagnostic différentiel pose problème. Il est important de reconnaître ces entités morbides comme telles parce qu'elles ne réagissent pas au traitement de la céphalée vasculaire de Horton, ou inversement; ainsi, l'hémicrânie paroxystique réagit à l'indométacine, mais non la céphalée de Horton. Un membre de la famille plus éloigné, l'hémicrânie chronique, réagit en général, mais pas toujours, à l'indométacine et ressemble parfois étrangement à la céphalée de Horton. Enfin, il est déjà arrivé que des céphalées hypnogènes, état morbide étranger à la famille des céphalées de Horton, aient dérouté quelques cliniciens qui avaient oublié qu'une anamnèse détaillée est essentielle au diagnostic des céphalées.

\section{Episodic cluster headache}

A 27-year-old man, in good general health despite a ten-year, pack-a-day cigarette habit, was referred because of 'intractable migraine'. His headaches that had begun about nine months ago had recurred at least twice every day for two months, and then had 'tailed off' over a few days and stopped completely. He had been free of headaches for the past six months when the headaches began again, and as before, they recurred two or three times each day and were of 'agonizing' intensity. His physician prescribed oral sumatriptan $100 \mathrm{mg}$ for each headache, which was stopped because of complete inefficacy, and then started him on propranolol $120 \mathrm{mg}$ bid.

All the headaches were centred in the right eye, building to a peak severity over a few minutes and persisting at extreme intensity for 30 to 40 mins before fading away over the next 3 to 4 mins. They always occurred within a couple of hours of going to bed at night, 'blasting' him out of sleep - he is now afraid to sleep. If he napped during the late afternoon, he would be aroused by a similar headache. A second or third headache would occur more or less unpredictably throughout the day. He would swear and pace the floor during headaches because of the severe pain; his right eye would water, and his right nostril would block. His wife claimed that his right eye would sometimes redden during a headache and that his right eyelid drooped.

His neurological examination was normal, but due to the possibility that he may have had a partial Horner's syndrome during his headaches, one wonders about a minimal and unconvincing droop of the right upper eyelid. Importantly, there was no trigeminal sensory loss to suggest an intracranial carotid lesion (such as an aneurysm, dissection or thrombosis) that impinged on the pericarotid sympathetic plexus and the first division of the trigeminal nerve (pericarotid or Raeder's syndrome).

Unlike most other entities in medicine, in episodic cluster headache, the 'full house' presentation exemplified by this patient was the rule rather than the exception. The following core features were noted:

Headaches clustered in time, occurring one to six times daily, often in association with the rapid eye movement stage of sleep, every day, lasting for weeks or months, and then ceasing spontaneously and completely until the next cluster months later.
Extremely severe headaches lasted 15 to 120 mins and were almost invariably in the same location (orbital, periorbital, cheek, temple) on the same side in every attack of that cluster.

Autonomic accompaniments of sympathetic deficiency (ocular Horner's syndrome) and parasympathetic overactivity (tearing, nasal stuffing or running, facial sweating, eyelid edema) were noted.

No abnormalities were observed on examination except occasional evidence of a slight partial persistent Horner's syndrome in sufferers with frequent attacks

Some other features, while suggestive, are not of great diagnostic weight. Eight times as many males than females have episodic cluster headaches. The age of onset is typically in the mid-20s to the early 30 s - later than that of migraine. Heavy smokers and drinkers are over-represented; many quit drinking during a cluster because alcohol triggers some of their headaches. A leonine (lion-like) face with coarse features and heavily creased facial skin is common in sufferers and has been attributed (with little evidence) to seratonin excess. Cluster patients are also prone to peptic ulceration, though this may relate more to their smoking and drinking.

In a minority of patients with cluster headache $(15 \%$ to $20 \%$ ), a cluster does not cease but keeps going indefinitely. When attacks recur for longer than one year without a remission, or with trivial remissions of less than 14 days, the patient is said to have 'chronic cluster headaches'. Cluster headaches are rarely chronic from the start. If they have never clustered, the diagnosis is evident from the stereotyped nature of the attacks, their number and their duration.

The clinical picture of cluster headache suggests the involvement of the trigeminovascular system (pain), the hypothalamus (biological clock) and the brainstem (parasympathetic features). Angiographic, positron emission tomography and magnetic resonance imaging (MRI) evidence supports this conjecture. Cluster headache, chronic and episodic paroxysmal hemicranias, short-lasting unilateral neuralgiform headache with conjunctival injection and tearing (SUNCT) syndrome and hemicrania continua appear to have similar pathophysiologies and roughly similar clinical features. For these reasons they have been placed together in the 
trigeminal autonomic cephalalgias (TACs) family (1). The treatment, however, has not been derived rationally from pathophysiological principles but has evolved empirically and is different from that of most TACs. Exact diagnosis, therefore, is an essential prelude to appropriate therapy.

On treating the acute attack of cluster headache, oral medication is at a disadvantage because its slow rate of absorption does not supply effective blood levels quickly enough to quell the fulminating pain. Injectable (intramuscular or intravenous) dihydroergotamine (DHE) 0.5 to $1.0 \mathrm{mg}$ works well, likely by activating the 5 -hydroxytryptamine ${ }_{1 \mathrm{~B} / \mathrm{D}}$ receptors in the trigeminovascular system. Nasal DHE (one spray into each nostril; repeat in 15 mins) is easier to self-administer, but may not be as effective. In a single study (2) it reduced the intensity but not the duration of the attacks. In older literature, inhaled ergotamine tartrate was found to be quite useful, but this formulation is often unavailable. The most widely used drug for treating acute attacks of cluster headache is sumatriptan $6 \mathrm{mg}$ self-administered subcutaneously. By using sumatriptan for each attack, the manufacturer's recommended limit of three doses per day may be exceeded; however, this is common practice and is defensible over the short term until prophylactic medication, begun simultaneously, can 'kick in' and remove the need for sumatriptan. Ergotamine, DHE and sumatriptan should not be prescribed until it has been established that there is no overt or occult heart disease - a significant consideration in the cluster headache population with its preponderance of men who smoke heavily.

An alternative to sumatriptan is inhaled oxygen. No one knows how it works, but taken through a well-fitting mask in $100 \%$ concentration at $7 \mathrm{~L} / \mathrm{min}$ for $15 \mathrm{mins}$, oxygen relieves cluster headache at least two-thirds of the time (3).

Lidocaine nose drops (4\%), $1 \mathrm{~mL}$ given in the nostril ipsilateral to the headache have been suggested as another alternative to sumatriptan. The aim is to anesthetize the spenopalatine ganglion that is believed to be an essential link in the pathogenesis of cluster headache. This treatment has never become widely used, possibly because its effectiveness seems infrequent and erratic.

Prophylaxis, medication taken every day to prevent attacks, is the backbone of therapy. The oldest prophylactic treatment, oral ergotamine daily, is still useful. Taken in a dose of $2 \mathrm{mg}, 2 \mathrm{~h}$ before bedtime, it may prevent the predictable nocturnal attacks that disrupt sleep. Because of its relatively short duration of action, it is not as effective for all-day prevention. Methysergide $2 \mathrm{mg}$ tid gives better all-day protection. It can be started in a dose of $2 \mathrm{mg}$ daily on the day of diagnosis (it can be used concurrently with sumatriptan) and can be increased by $2 \mathrm{mg} /$ day until the tid dosage is reached, with an expected effect within two to five days. It should be continued with the patient who is symptom-free for the expected duration of a cluster - usually three or four months. Because of the occasional occurrence of vasoconstriction, methysergide and ergotamine must not be used in patients with peripheral or cardiovascular disease. Methysergide should not be given continuously for more than six months without removing treatment for at least one month, because of the possibility of fibrotic complications of the serosa (peritoneum, pleura, pericardium, endocardium); however, this is seldom a consideration in cluster headache where, chronic cluster excepted, spontaneous remissions may be expected after three or four months.

Corticosteroids are as fast as methysergide in relieving a cluster. Prednisone, started in a dose of 60 to $80 \mathrm{mg} / \mathrm{day}$, abolishes headaches within two to four days. After which the dose is reduced slowly. The headaches often come raging back when the dose falls to 20 to $25 \mathrm{mg} /$ day, and it becomes a matter of titrating to observe the lowest dose to keep the patient headache-free. Depending on the general health of the patient, it may not be prudent to start corticosteroids or, alternatively, to continue them beyond a few weeks. Young, healthy patients can tolerate them for the three- to four-month duration of a cluster if followed closely.

Other prophylactic agents are much safer for use in older patients and for long term use but have the disadvantage of being much slower to take effect. The calcium channel blocker verapamil 80 to $120 \mathrm{mg}$ tid may take two to four weeks to attain efficacy, and flunarizine requires eight to 10 weeks. The anticonvulsant sodium valproate, taken 500 to $2000 \mathrm{mg} /$ day, may take three to six weeks to suppress headaches; this depends on how quickly and carefully the dose of $300 \mathrm{mg}$ (one tablet)/day is increased, while monitoring serum lithium levels to keep them under $1.0 \mathrm{mmol} / \mathrm{L}$. The dose may be increased to as much as $300 \mathrm{mg}$ tid and may take two to three weeks to work.

Because of these time-to-efficacy characteristics, many neurologists start simultaneous triple therapy as soon as they diagnose the cluster headache.

Self-administered subcutaneous sumatriptan $6 \mathrm{mg}$ at the onset of each headache to a maximum of five injections per day. If sumatriptan use exceeds this, or is contraindicated, then the patient may inhale oxygen through a well-fitting mask in $100 \%$ concentration at $7 \mathrm{~L} / \mathrm{min}$ for 15 mins with each headache.

Prednisone 60 to $80 \mathrm{mg} /$ day, tapering over six to 10 days to the lowest dose that suppresses the headaches, or methysergide $2 \mathrm{mg}$ tid to four times daily. These are used for a quick 'knock down', are continued until the more slow onset medications (described below) have been in play for long enough to start working (usually weeks), and then are tapered and discontinued.

Verapamil 80 to $120 \mathrm{mg}$ tid, valproate 500 to $2000 \mathrm{mg} /$ day or lithium carbonate in a maximum dose of $300 \mathrm{mg}$ tid (blood levels between 0.8 to $1.0 \mathrm{mmol} / \mathrm{L}$ ). These are given to keep the headache down, and are tapered and stopped at the expected end of the cluster, or in the case of chronic cluster, every six months to see if the headaches have ceased. 
About $10 \%$ of people with cluster headache, especially some of those with chronic cluster, either do not respond to medications, stop responding to them after initial success, or develop dangerous, incapacitating side effects from them. For these unfortunate individuals, a number of surgical treatments have been tried, including radio frequency lesions of the trigeminal ganglion or of the sphenopalatine ganglion, gamma knife surgery on the trigeminal root, microvascular decompression of the trigeminal nerve or of the nervus intermedius, and frank sectioning of the nervus intermedius in various permutations and combinations. Only about $50 \%$ of patients have an acceptable result (4). This rather disheartening score card mirrors the fundamental paucity of knowledge about the pathophysiology of this debilitating affliction.

\section{Chronic paroxysmal hemicrania}

A 26-year-old woman was referred because of intractable 'cluster headaches'. They had begun about a year ago and recurred eight to 12 times per day, every day, in stereotyped attacks, each lasting 15 to 30 mins. Her headaches occurred at any time of the day or night. They centred around the left eye and were extremely severe, causing her to 'freeze in her tracks'. Each headache was accompanied by watering of the painful eye and stuffy nose. Her husband and colleagues noted that her left eye was red during headaches, even though she did not rub it. Subcutaneous sumatriptan did not abort the attacks, and trials of prednisone, methysergide and verapamil in doses for adequate duration were unhelpful. Her failure to respond to therapy prompted imaging (MRI and magnetic resonance angiography), which was normal. Her neurological examination was normal.

The patient's sex, and high frequency and relative brevity of attacks suggested a diagnosis of chronic paroxysmal hemicrania (CPH). Indomethacin $25 \mathrm{mg}$ was given the first day, $25 \mathrm{mg}$ bid the next and $25 \mathrm{mg}$ tid thereafter, always with food. Headaches decreased in frequency on the fifth day, but improvement stalled until the dose was gradually increased to $125 \mathrm{mg}$ /day, when the headaches ceased. Two weeks later, she developed abdominal pain and stopped the medication; her headaches returned within $36 \mathrm{~h}$. Advice regarding consistently taking the indomethacin with food was reiterated, she was started on misoprostol $400 \mu \mathrm{g} / \mathrm{day}$, and the indomethacin was resumed in its former dosage. Her headaches disappeared in $48 \mathrm{~h}$.

As with close relatives in any family, cluster headache and $\mathrm{CPH}$ are liable to be confused with each other. The clues for identifying $\mathrm{CPH}$ are that most patients are women (three to one), the attacks are more frequent than those of cluster headaches (average six to 12/day and sometimes as many as 40 ) and the headaches are briefer ( 2 to 45 mins as opposed to 15 to 180 mins for cluster headaches). There is, however, considerable overlap. In terms of location and accompaniments, cluster headache and CPH are nearly identical; therefore, mistakes are inevitable. Differentiation can be even more difficult in the rarer condition, episodic paroxysmal hemicrania $(\mathrm{EPH})$, where the attacks cluster in time, with clusters separated by weeks or months of spontaneous remis- sion. Despite its close family resemblance to cluster headache, $\mathrm{EPH}$, like its sister $\mathrm{CPH}$, responds only to indomethacin. Thus, it is good policy when dealing with assumed cluster headache that has not responded to adequate doses of multiple cluster medications to first conduct neuroimaging to rule out carotid artery, sellar and cavernous sinus lesions that may mimic cluster headache and then start indomethacin. Do not accept that indomethacin has not been effective until there has been no response to $200 \mathrm{mg} /$ day (though most people with CPH or EPH respond to a lower dose).

\section{SUNCT syndrome}

For the past three years, a 52-year-old male had between five and 30 attacks of severe pain every day, in and around the right eye, coming on at any time of the day or night. He related them to, "someone sticking a knife in my eye". Fortunately, they lasted only 10 to $20 \mathrm{~s}$ each, but their unpredictability caused him great distress. During the attacks and for a while afterward, the right eye watered and was red. His neurological examination was normal. Because of the unusual nature of these attacks, his physician arranged a computed tomography scan to exclude lesions. He was referred to a neurologist, who was equally puzzled and arranged for an MRI and angiography, which were also normal. A trial of carbamazepine for trigeminal neuralgia was unhelpful, as were trials of corticosteroids and methysergide for cluster headache and indomethacin for $\mathrm{CPH}$. His ultrafrequent, ultrashort headaches continued.

These SUNCT headache attacks, though likely members of the TAC family, do not respond to indomethacin. In fact, they do not respond to any medication. Fortunately, SUNCT is very rare. Because of the great rarity of the condition and the possibility that a posterior fossa lesion may produce similar symptoms, it is advisable to image a patient believed to have SUNCT.

Forffbenparsisia gentingaa38-year-old woman had a continuous dull pain in the left side of her head. When it started seven or eight years ago, it seemed to occur episodically, lasting two or three weeks at a time, with periods of up to a month free of headaches, but the episodic headaches occurred in increasing frequency and lasted for increasingly longer durations, ultimately fusing into one headache that persisted. It is now dull, low grade and continuous, but superimposed upon it as exacerbations, occurring about 12 times each month and lasting 8 to $14 \mathrm{~h}$ at a time, in which the headache is clearly more severe and is accompanied by redness and watering of the left eye, drooping of the left eyelid and stuffy nose. She was taking over-the-counter analgesics regularly, and her family physician persuaded her to give these up, but after six weeks off all analgesics she was absolutely no better. The exacerbations have not responded to zolmitriptan or to naratriptan, and adequate trials of prophylaxis with proranolol, amitriptyline, sodium valproate and methysergide failed. The referring physician arranged an enhanced CT scan of the head; the results were normal. The neurological examination was also normal.

The patient was started on a low dose of indomethacin, 
TABLE 1

Cluster and cluster-like headaches

\begin{tabular}{|c|c|c|c|c|c|c|}
\hline & Cluster headaches & $\mathrm{CPH}$ & EPH & $\mathrm{HC}$ & SUNCT & Hypnic headaches \\
\hline Sex (female:male) & $1: 8$ & $3: 1$ & $1: 1$ & $2: 1$ & $1: 8$ & $2: 1$ \\
\hline Site of pain & Orbit, temple & Orbit, temple & Orbit, temple & Hemicranium & Orbit & Bilateral \\
\hline Attack frequency & 1 to $8 /$ day & 1 to $40 /$ day & 3 to $30 /$ day & Variable & Up to $30 / \mathrm{h}$ & 1 to $3 /$ night \\
\hline Attack duration & 15 to 180 mins & 2 to 45 mins & 1 to 30 mins & Minutes to days & 10 to $20 \mathrm{~s}$ & 15 to 30 mins \\
\hline Autonomic features & Prominent & Prominent & Prominent & Present & Prominent & Absent \\
\hline
\end{tabular}

CPH Chronic paroxysmal hemicrania; EPH Episodic paroxysmal hemicrania; HC Hemicrania continua; SUNCT Short unilateral neuralgiform headaches with conjunctival injection and tearing. Adapted with permission from reference 6

$25 \mathrm{mg} /$ day, that was slowly increased to $50 \mathrm{mg}$ tid, and her headaches ceased.

Hemicrania continua is a difficult diagnosis. It may be imitated closely by analgesic rebound headaches on the 'benign' end of the spectrum, and on the 'malignant' end may be mimicked by space-occupying lesions or arteriovenous malformations. It is a member of the TAC family and, like most of its relatives, responds to indomethacin. Why most members of the TAC family respond to indomethacin and not to other nonsteroidal anti-inflammatory drugs, even in large doses, is a mystery.

\section{Hypnic headaches}

For the past eight months, a 67-year-old male had been awakened once or twice almost every night by bilateral, throbbing, moderately severe headaches that ceased within 20 mins. There were no accompanying symptoms such as nausea, vomiting, change in the appearance of his eyes, stuffy nose or runny nose. The headaches had not been aborted by two trials of oral triptans, and have not been prevented by trials of amitriptyline, valproate, indomethacin or methysergide. Enhanced CT scan showed no evidence of a space-taking lesion. Inspection of his dwelling showed no evidence of any source of carbon monoxide, and his arterial blood gases were normal. Lithium carbonate $300 \mathrm{mg}$ every night abolished the headaches.

Because their occurrence is strictly nocturnal, appearing to rise out of rapid eye movement sleep, hypnic headaches may be confused with cluster headaches even though the complete absence of any autonomic features and the bilaterality of the headaches militate strongly against this diagnosis (5). These rare hypnic headaches are not members of the TAC family and do not respond to indomethacin. Most cases respond to lithium, but the few that do not may respond to valproate; some do not respond to any treatment. Nocturnal headaches, particularly in the elderly, who are susceptible to hypnic headaches, are frequently produced by carbon dioxide retention in chronic chest disease, by carbon monoxide from defective heating systems or from intracranial mass lesions (6). Therefore, hypnic headache is a diagnosis that should be made only after thorough investigation has excluded these.

\section{CONCLUSIONS}

TACs are a family of disorders in which intermittent dysfunction of parts of the central nervous system simultaneously activate autonomic phenomena and neurovascular headache. Hypothalamic involvement imparts a periodicity or rhythmicity to the symptoms that is helpful in clinical diagnosis. The nature of the central nervous system dysfunction is unknown, but it does not appear to be genetically determined; while a paratrigeminal, sellar or posterior fossa lesion may mimic the TACs, no structural basis has been conclusively demonstrated for them.

Members of the TAC family are similar, but each is recognizably different (Table 1) (7). Because treatment varies according to the type of TAC, precise diagnosis is essential, but because no biochemical or imaging 'markers' have been observed, this is not always possible. In the event of diagnostic confusion, a suggested rule of thumb is that any unilateral headache that does not fulfill the International Headache Society's diagnostic criteria for migraine, and that is regularly accompanied by autonomic phenomena should, after appropriate investigation to exclude a lesion, be suspected of being a member of the TAC family and should have a therapeutic trial of cluster treatment (8). If this is unsuccessful, follow-up with treatment using indomethacin is indicated.

\section{REFERENCES}

1. Goadsby PJ, Lipton RB. A review of paroxysmal hemicranias, SUNCT syndrome and other short-lasting headaches with autonomic feature, including new cases. Brain 1997;120:193-209.

2. Andersson PG, Jespersen LT. Dihydroergotamine nasal spray in the treatment of attacks of cluster headache. Cephalalgia 1986;6:51-4. 
3. Fogan L. Treatment of cluster headache. A double-blind comparison of oxygen v air inhalation. Arch Neurol 1985;42:362-3.

4. Lovely TJ, Kotsiakis X, Janette PJ. The surgical management of chronic cluster headache. Headache 1998;38:590-4.

5. Dodick DW, Mosek AC, Campbell JK. The hypnic ("alarm clock") headache syndrome. Cephalalgia 1998;18:152-6.

6. Edmeads J. Headache in the elderly. In: Olesen J, Tfelt-Hansen P,
Welch KMA, eds. The Headaches, 2nd edn. Philadelphia: Lippincott Williams and Wilkins, 2000:977-51.

7. Giammarco R, Edmeads J, Dodick D. Critical Decisions in Headache Management. London: BC Decker Inc, 1998:94.

8. Headache Classification Committe of the International Headache Society. Classification and diagnositic criteria for headache disorders, cranial neuralgias and facial pain. Cephalalgia 1998;8:1-96. 


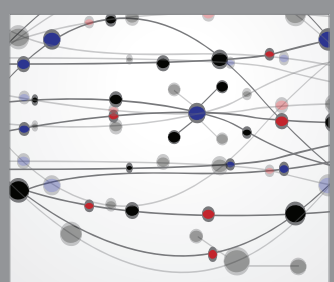

The Scientific World Journal
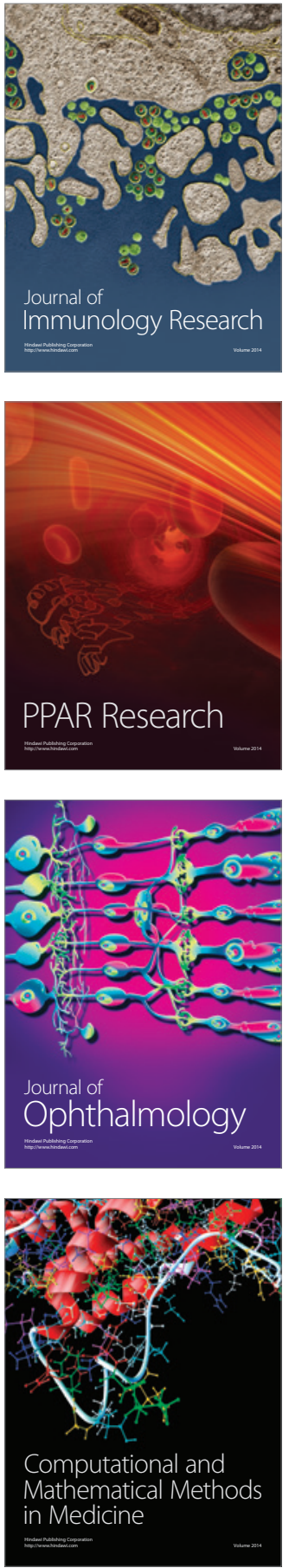

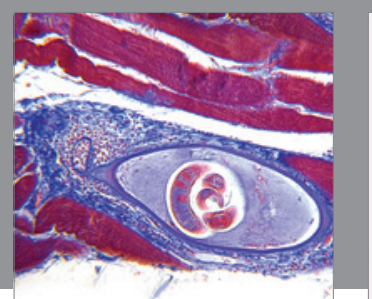

Gastroenterology Research and Practice

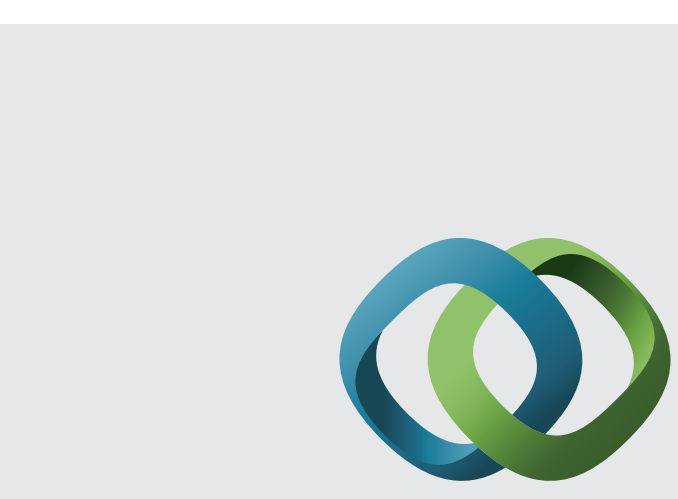

\section{Hindawi}

Submit your manuscripts at

http://www.hindawi.com
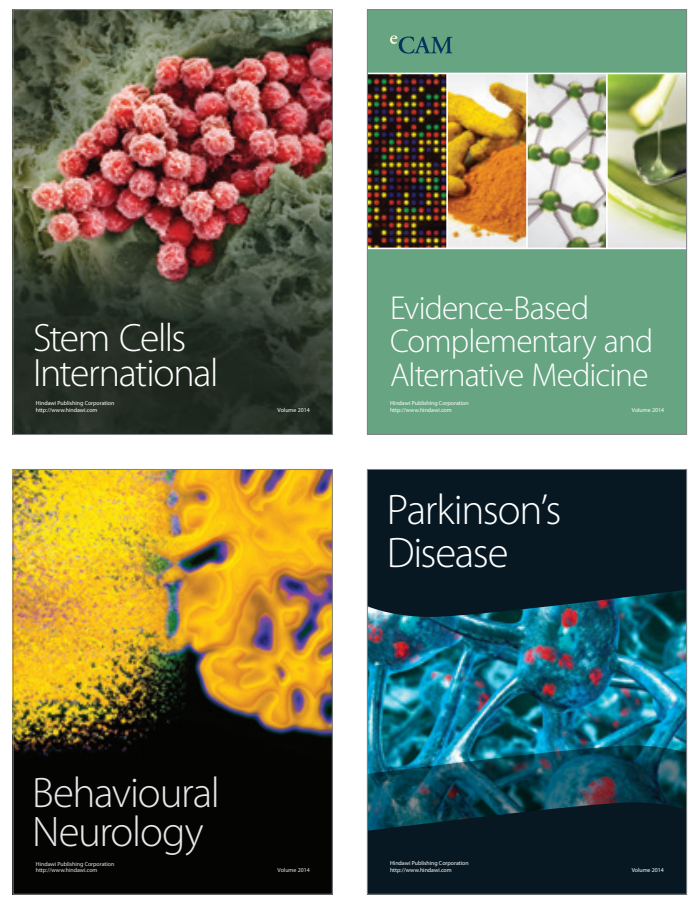
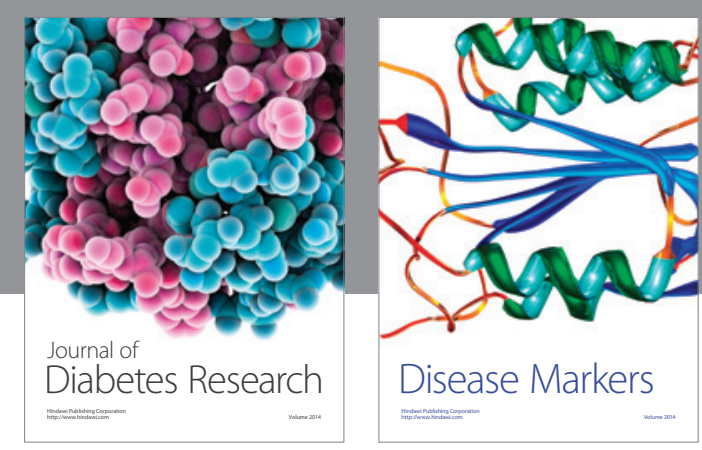

Disease Markers
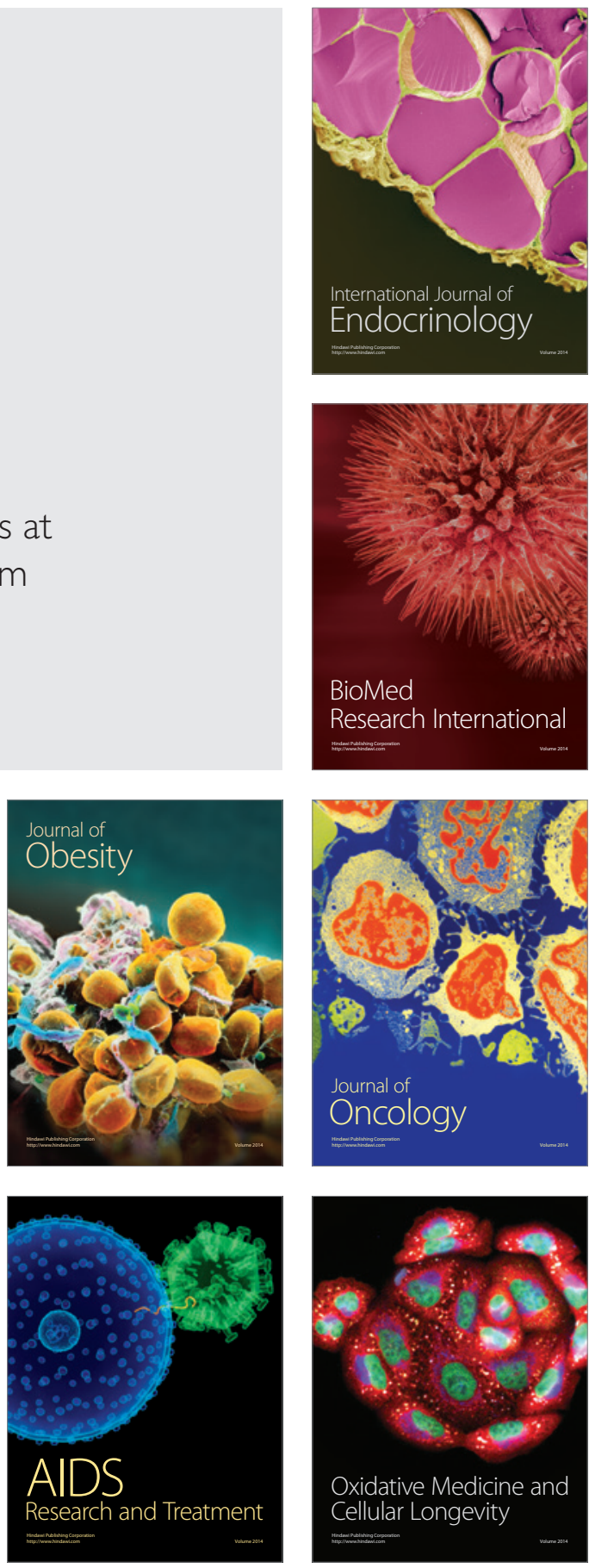